\title{
Assembly-diassembly-organisation-reassembly synthesis of zeolites based on cfi-type layers
}

\author{
Daniel S. Firtha, Samuel A. Morris ${ }^{a}$, Paul S. Wheatley ${ }^{a}$, Samantha E. Russella, Alexandra M. Z. \\ Slawin $^{a}$, Daniel M. Dawson ${ }^{\mathrm{a}}$, Alvaro Mayoral ${ }^{\mathrm{b}}$, Maksym Opanasenko ${ }^{\mathrm{c}, \mathrm{d}}$, Miroslav Položij ${ }^{\mathrm{d}}$, Jiři \\ Čejkac, Petr Nachtigall ${ }^{\mathrm{d}}$ and Russell E. Morris ${ }^{*, a, d}$ \\ ${ }^{a}$ EaStCHEM School of Chemistry, University of St Andrews, St Andrews KY16 9ST, UK \\ bNanoscience Institute of Aragon (INA), Advanced Microscopy Laboratory (LMA), University of Zaragoza, Spain. \\ 'J. Heyrovský Institute of Physical Chemistry, Academy of Sciences of the Czech Republic, v.v.i., Dolejškova 3, 18223 \\ Prague 8, Czech Republic \\ ${ }^{d}$ Department of Physical and Macromolecular Chemistry, Faculty of Science, Charles University, Hlavova 2030/8, \\ 12843 Prague 2, Czech Republic.
}

\begin{abstract}
The hydrothermal synthesis of a zeolite, with properties suitable for use in the ADOR (AssemblyDisassembly-Organisation-Reassembly) process, has been designed and a zeolite, called SAZ-1, successfully prepared. This zeolite has then been used as a parent in the ADOR process and two new daughter zeolites, IPC-15 and IPC-16, have been prepared. The X-ray powder diffraction patterns of the new zeolites match well those predicted using computational methods. The three materials, form an isoreticular series with decreasing pores size from 14-ring to 12-ring to 10-ring.
\end{abstract}

\section{INTRODUCTION}

Hydrothermal synthesis has a long history of success in zeolite (and other materials) synthesis. ${ }^{1}$ The design of new zeolitic frameworks depends on the combination of several important features, such as the chemical composition of the framework and how this affects structural units in the final solid, and the use of structure directing agents to determine how much porosity is available in the final material. ${ }^{1-3}$ The combination of chemical composition with porous topologies is what makes zeolites so industrially successful. ${ }^{4}$ However, recently it has become clear that hydrothermal synthesis has limitations in the types of zeolite that it can produce. ${ }^{5}$ In particular, the reversibility of the crystallization process that forms the final framework always offers a pathway by which the system can avoid higher energy arrangements, leading to the famous energy-density correlation that is seen for hydrothermally prepared zeolites. ${ }^{6-9}$ This means that the vast majority of theoretical zeolite structures (of which there are several millions) are deemed as being of 'low feasibility' or 'unrealistic synthesis targets' ${ }^{6,7}$ One way to avoid this limitation is to use a new synthesis mechanism where the final framework formation step is an irreversible condensation reaction that does not allow the system to avoid higher energy arrangements. ${ }^{8,9}$ The recent development of the ADOR process shows how this can provide entirely new types of zeolite that would have previously been thought of as unfeasible synthesis targets. ${ }^{10}$
Unlike the direct hydrothermal crystallization of zeolites the ADOR process is a stepwise assemblydisassembly-organization-reassembly process that manipulates zeolite structures to form new ones. This has resulted in the discovery of several new all-silica zeolites, produced from parent germanosilicates whose framework were already known (such as UTL and UOV). ${ }^{11,12}$ The ADOR process requires a parent zeolite with a specific set of chemical and framework properties in order to be successful. Consequently, it is not possible to apply the ADOR process to the majority of known zeolite frameworks. It is therefore imperative to synthesize new parent germanosilicates, able to undergo the ADOR process, so as to increase the number of possible new frameworks.

In this contribution, we show how traditional hydrothermal synthesis and the ADOR process have been combined. We produce a parent zeolite by designing a hydrothermal synthesis where we specifically target a new material that is suitable for further manipulation using the ADOR process. This means that the number of new zeolites possible from a single hydrothermal preparation is amplified - rather than each successful synthesis providing only one new zeolite, we show how one hydrothermal synthesis can provide potentially three new materials - a parent and two daughters - all of which have different structures. However, because the daughter structures are propagated from the parent, they are closely related, forming an isoreticular series of materials having the 
same basic network topologies but with differing pore sizes.

Design Principles. To design, a priori, a hydrothermal synthesis that will produce a material suitable for further manipulation using the ADOR process one must maximise the likelihood of producing the necessary structural and compositional features in the final product. ${ }^{13}$ For the ADOR process to be applied the parent zeolite should have silica-rich layers joined by a 'weak' building unit that can be removed during the disassembly phase of the ADOR process. ${ }^{8}$ Experience has shown that germaniumrich double four rings $\left(\mathrm{D}_{4} \mathrm{R}\right)$ are an excellent target for these linking units for two reasons. Firstly, the larger size of germanium compared to silicon means that it preferentially occupies $\mathrm{D}_{4} \mathrm{R}$ units, leading to silica-rich layers linked by germanium-rich $\mathrm{D}_{4} \mathrm{R}$ units. ${ }^{14}$ Secondly, O-Ge-O bonds in zeolites are much more hydrolytically sensitive than their O-Si-O counterparts, meaning that the $\mathrm{D}_{4} \mathrm{R}$ units can be preferentially removed from zeolite parents. ${ }^{9}$ Germanium added to a zeolite synthesis often helps to promote the formation of $\mathrm{D}_{4} \mathrm{R}$ units, but the probability of their formation can be further enhanced by the addition of fluoride ions, which also promotes the formation of $\mathrm{D}_{4} \mathrm{R}$ units. ${ }^{15,16}$

Since the ADOR process works through the selective removal of the $\mathrm{D}_{4} \mathrm{R}$ units, it is also advantageous to have the original hydrothermal synthesis provide a material with large pores, which allows the most opportunity to remove structural units and still produce highly porous zeolites after disassembly/reassembly. Such a synthesis requires a fairly large, bulky organic structure-directing agent (SDA) to provide the large pores required for the parent material.

Here we show how a designed synthesis, using a new SDA and including Ge and fluoride in the reaction, produces a zeolite, that we call SAZ-1, which we can then use the ADOR process to make two new zeolite topologies.

\section{EXPERIMENTAL SECTION}

Materials. All chemicals were commercially sourced and used without further purification: 1(chloromethyl)naphthalene, 94\%, Alfa Aesar;

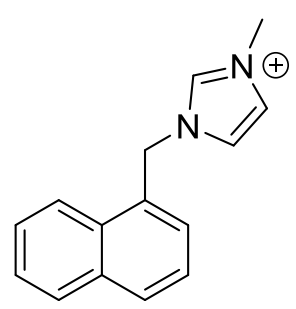

Figure 1. 1-methyl-3-(napthalen-1-ylmethyl)imidazolium organic cation determined to show the ideal properties discussed in our design principles for the synthesis of an ADORable zeolite.
1-methyl-1H-imidazole, $99 \%$, Aldrich; Ambersep ${ }^{\circledR}$ 9oo, $\mathrm{OH}$ form ion-exchange resin, Acros Organics; Diethoxydimethylsilane, 97\%, Acros Organics; Germanium(iv) oxide, $99.999 \%$. Alfa Aesar; Hydrofluoric acid, 48 wt. \%, Sigma-Aldrich; Octylamine, $99 \%$, Aldrich; Tetraethyl orthosilicate, $98 \%$, Aldrich and Cab-O-Sil M5 ${ }^{\mathrm{TM}}$, Acros Organics.

Synthesis of SDA. Synthesis of the new organic SDA was based on a modified synthesis of a previous SDA used by Chen et al. ${ }^{17}$ 1-(chloromethyl)naphthalene (58.425 g, $330 \mathrm{mmol}$ ) was placed in THF $(250 \mathrm{~mL})$ with subsequent addition of a stoichiometric amount of 1-methyl-1Himidazole $(31.35 \mathrm{~mL}, 330 \mathrm{mmol})$ and refluxed for 3 days. The resulting white solid was filtered and washed with more THF and allowed to dry overnight yielding a white solid, which was determined pure by ${ }^{1} \mathrm{H}$ NMR Figure $\mathrm{S} 1$ (yield $=72.5 \mathrm{~g}, 84.9 \%$ ). The chloride salt was then converted to the hydroxide salt by anion exchange. The final concentration of the ion exchange was determined by titration with $\mathrm{HCl}(0.1 \mathrm{M})$, the yields of the ion exchange were over $90 \%$.

Synthesis of zeolite SAZ-1. The synthesis of the zeolite consisted of adding germanium oxide (1.046 $\mathrm{g}, 10 \mathrm{mmol})$ to a stirring solution of the anion exchanged SDAOH (10 $\mathrm{mmol})$. After 30 minutes tetraethylorthosilicate $(4.47 \mathrm{~mL}$, $20 \mathrm{mmol})$ or Cab-O-Sil M5 $5^{\mathrm{TM}}(1.202 \mathrm{~g}, 20 \mathrm{mmol})$ was added and the solution stirred overnight to allow for hydrolysis of the TEOS and/or loss of water. HF solution $(0.725 \mathrm{~mL}$, $20 \mathrm{mmol}$ ) was then added and the gel was allowed to reach the desired water ratio by evaporation resulting in a final molar composition of $1 \mathrm{SiO}_{2}: 0.5 \mathrm{GeO}_{2}: 1$ SDAOH : 1 $\mathrm{HF}: 10-2 \mathrm{O} \mathrm{H}_{2} \mathrm{O}$. The resultant white paste was placed in a Teflon lined autoclave and heated at $150{ }^{\circ} \mathrm{C}$ for 14 days. The final product was then filtered and washed with distilled water and finally ethanol. The product was then calcined at $575{ }^{\circ} \mathrm{C}$ to produce the SDA-free germanosilicate.

Hydrolysis of SAZ-1. The calcined zeolite (0.50 g) was placed in $0.1 \mathrm{M} \mathrm{HCl}(100 \mathrm{~mL})$ and heated at $95{ }^{\circ} \mathrm{C}$ for 16 hours. The resultant solid was filtered, washed with distilled water and dried. The recovered product is named SAZ-1P (yield $=0.324 \mathrm{~g}$ ).

Synthesis of IPC-15 and IPC-16. For IPC-15 SAZ-1P $(0.324 \mathrm{~g})$ was placed in octylamine $(20 \mathrm{~mL})$. This was then stirred at $70{ }^{\circ} \mathrm{C}$ for 3 hours followed by room temperature overnight. The product was then filtered, washed and calcined at $575{ }^{\circ} \mathrm{C}$ (yield $=0.242 \mathrm{~g}$ ). For IPC-16 SAZ-1P $(0.324 \mathrm{~g})$ was placed in an autoclave containing $1 \mathrm{M} \mathrm{HNO}_{3}$ $(20 \mathrm{~mL})$ and diethoxydimethylsilane (0.05 g) stirred at room temperature for 10 minutes and heated at $175{ }^{\circ} \mathrm{C}$ for 16 hours. The product was then filtered and washed with water and calcined at $575{ }^{\circ} \mathrm{C}$ (yield $=0.234 \mathrm{~g}$ ).

Characterization. Liquid State ${ }^{1} \mathrm{H}$ NMR was recorded on a Bruker AVII 400 using $\mathrm{D}_{2} \mathrm{O}$ as the solvent. Solid-state 
NMR spectra were recorded using a Bruker Avance III spectrometer equipped with a $9.4 \mathrm{~T}$ superconducting magnet (Larmor frequencies of $400.1 \mathrm{MHz}$ for ${ }^{1} \mathrm{H}$ and 79.5 $\mathrm{MHz}$ for ${ }^{29} \mathrm{Si}$ ). Samples were packed into standard $\mathrm{ZrO}_{2}$ rotors with outer diameters of $4 \mathrm{~mm}$ and rotated at the magic angle at $10 \mathrm{kHz}$. The ${ }^{29} \mathrm{Si}$ MAS NMR spectrum of SAZ-1 was recorded with signal averaging for 496 transients with a recycle interval of $120 \mathrm{~s}$. The ${ }^{29} \mathrm{Si}$ CP MAS NMR spectrum of SAZ-1 was recorded with signal averaging for 1024 transients with a recycle interval of $5 \mathrm{~s}$. A spin lock of $0.5 \mathrm{~ms}$ was used, with a ramped pulse $(90-100 \%)$ applied to ${ }^{1} \mathrm{H}$. High-power $\left(v_{1}=100 \mathrm{kHz}\right)$ TPPM-15 ${ }^{1} \mathrm{H}$ decoupling was applied during acquisition. The ${ }^{29} \mathrm{Si}$ MAS NMR spectra of SAZ-2 and SAZ-3 were recorded with signal averaging for 1336 (SAZ-2) and 1360 (SAZ-3) transients with a recycle interval of $60 \mathrm{~s}$. The ${ }^{29} \mathrm{Si} \mathrm{CP}$ MAS NMR spectra of SAZ-2 and SAZ-3 were recorded with signal averaging for 2048 transients with a recycle interval of 3 s. A spin lock of $0.5 \mathrm{~ms}$ was used, with a ramped pulse $(90-100 \%)$ applied to ${ }^{1} \mathrm{H}$. High-power $\left(v_{1}=80 \mathrm{kHz}\right)$ TPPM-15 ${ }^{1} \mathrm{H}$ decoupling was applied during acquisition. Chemical shifts are reported in ppm relative to TMS using forsterite $(\alpha-$ $\mathrm{Mg}_{2} \mathrm{SiO}_{4}, \delta=-62 \mathrm{ppm}$ ) as a secondary solid reference.

PXRD were collected on either a PANalytical Empyrean diffractometer operated in reflection, Bragg Brentano, $\theta$ $2 \theta$ mode utilizing $\mathrm{Cu} K \alpha$ radiation or on a STOE STADIP diffractometer operated in Debye Sherrer mode utilizing $\mathrm{Cu} \mathrm{K} \alpha$ radiation. Synchrotron PXRD data were collected on beam line In at Diamond Light Source, U.K. A wavelength of $0.826048 \AA$ and a Mythen II PSD detector were used to collect data from $2-90^{\circ} 2 \theta$. All Pawley refinements were carried out in the program TOPAS Academic v5.23 TGA experiments were measured on a Netzsch TG 209 instrument under air. The samples were heated in alumina crucibles at the heating ramp of $10{ }^{\circ} \mathrm{Cmin}^{-1}$. Adsorption isotherms of nitrogen at $-196^{\circ} \mathrm{C}$ were determined using an ASAP 2020 (Micromeritics) static volumetric apparatus. Before the adsorption experiments, the samples were degassed under a turbomolecular pump vacuum at a temperature of $250{ }^{\circ} \mathrm{C}$ for eight hours. SEM images were recorded with a Jeol JSM-560o scanning electron microscope. A tungsten filament electron gun was used. The operating voltage was $25 \mathrm{kV}$. Chemical composition analysis EDX was carried out with an Oxford Inca Energy system on the same SEM instrument at the operating voltage of $25 \mathrm{kV}$. Spherical aberration corrected $\left(\mathrm{C}_{\mathrm{s}^{-}}\right.$ corrected) scanning transmission electron microscopy (STEM) - high annular dark field (HAADF) measurements were performed using an X-FEG TITAN FEI 6o-300 transmission electron microscope operated at $300 \mathrm{kV}$. The column was fitted with a CEOS spherical aberration corrector for the electron probe which was aligned using a gold standard sample prior to every experiment, assuring a nominal point resolution of $0.8 \AA$ A. The microscope also incorporated a Gatan Tridiem energy filter, an EDAX EDS and a Fischione HAADF detector. The half-angle employed was 17.5 mrad.

\section{RESULTS AND DISCUSSION}

Preparation of Parent Germanosilicate. Taking the design principles previously discussed into account we designed a synthesis that we predicted would be most likely to provide a germanosilicate zeolite with the correct structural features, using the naphthalene derivative 1methyl-3-(naphthalen-1-ylmethyl)-imidazolium cation structure shown in Figure 1. This SDA was synthesized as described in the experimental and was confirmed by liquid state ${ }^{1} \mathrm{H}$ NMR (Figure $\mathrm{S}$ ). Using the synthesis composition and conditions described above we successfully prepared a zeolitic framework with the desired chemical and framework properties for the ADOR process. X-ray powder diffraction of the white powder recovered from the hydrothermal synthesis revealed that the bulk of the sample is a highly crystalline solid, with a small amount $(<5 \%)$ of a poorly crystalline impurity. This pattern was later found to match that of CIT-13 and NUD-2 (Figure S2.), which were published after we began this project. ${ }^{18,19}$

From SEM/EDX analysis we confirmed the presence of germanium and the rectangular thin-plate morphology of the sample (Figure $S_{3}$ ). These results also indicated that the size of the single crystals was suitable for single crystal X-ray diffraction experiments. TGA analysis showed that SAZ-1 had a weight loss (24.8\%) consistent with the presence of the organic SDA in the as made sample (Figure $\mathrm{S}_{4}$ ). Solid-state ${ }^{13} \mathrm{C}$ NMR confirmed the presence of the intact SDA (Figure $\mathrm{S}_{5}$ ) within the zeolite framework.

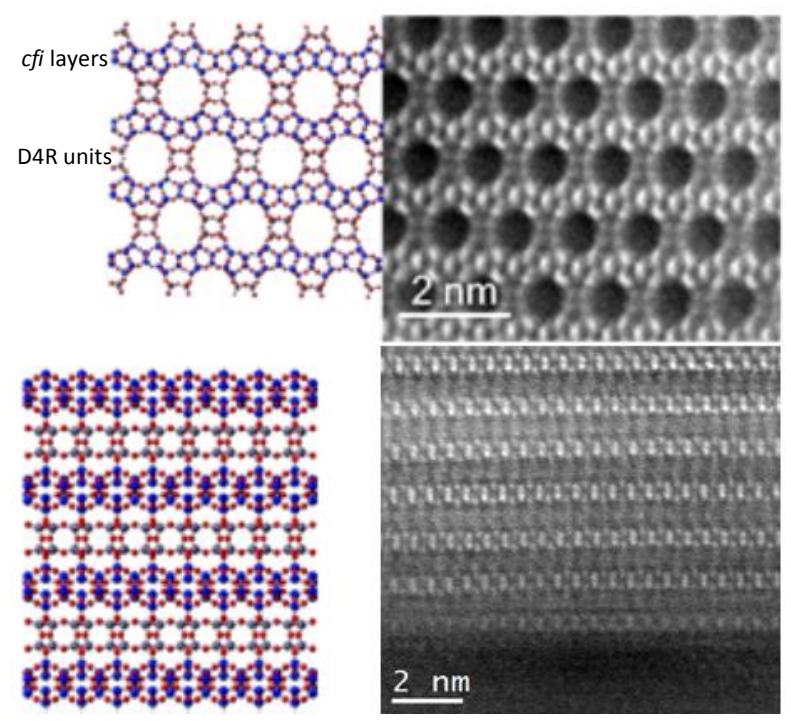

Figure 2. Structure of SAZ-1 viewed parallel to the 14 membered ring channels (oor direction) showing the silica-rich $c f$-type layers linked by the $\mathrm{D}_{4} \mathrm{R}$ units. The structure derived from single crystal X-ray diffraction is overlaid on the atomic resolution HAADF-STEM image of SAZ-1, showing a clear correlation (Top). A view of SAZ-1 parallel to the 10-ring channels, showing that the silicarich layers are linked by disordered layers of germaniumrich $\mathrm{D}_{4} \mathrm{R}$ units (bottom). 


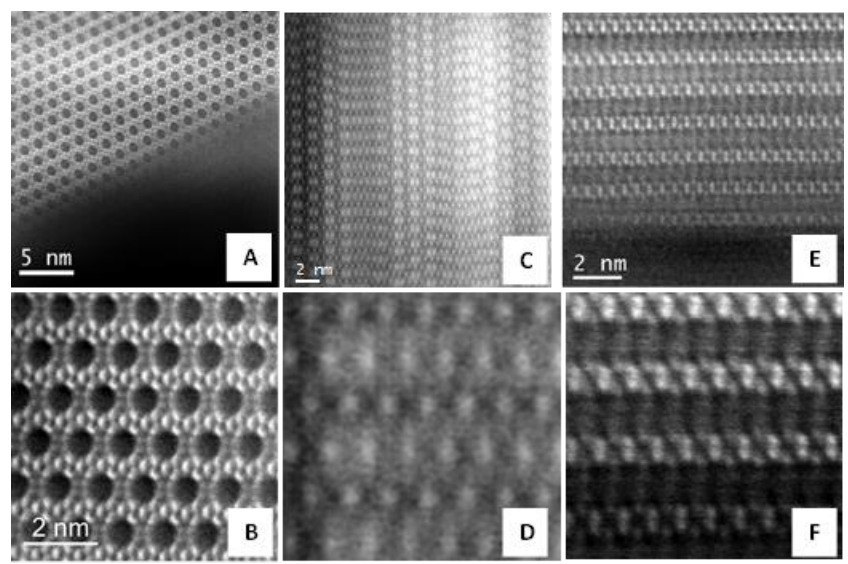

Figure 3. HADDF STEM images of SAZ-1. The oor direction (A and $B$ ) show the presence of well-ordered 14 ring pores formed by the connection of the silicate layers with $\mathrm{D}_{4} \mathrm{R}$ units. The 110 direction $(\mathrm{C}$ and $\mathrm{D})$ shows the large amount of density looking through the layer and $\mathrm{D}_{4} \mathrm{R}$ units, this also shows the disorder present in this direction. The o1o direction ( $\mathrm{E}$ and $\mathrm{F}$ ) shows the presence of the silicate layers, but a blurring where the 10 ring pores should be indicating the disorder present in this direction Larger images with the structure projections can be seen in Figure S6.

The structure of the material was solved from a small single crystal of the material using direct methods and refined using least-squares methods to reveal the structure shown in Figure 2. SAZ-1 showed the desired structural features for the ADOR process - silica-rich layers that are linked into a three-dimensional structure through germanium-rich $\mathrm{D}_{4} \mathrm{R}$ units. However, the $\mathrm{D}_{4} \mathrm{R}$ units that connect the layers are disordered over two possible sites. The structure has 14-ring channels running parallel to the crystallographic c-axis (Figure 2), confirming the choice of SDA as a good one, and justifying the choice of chemistry as being likely to produce the predicted large pore sizes. The refined framework structure is the same as the very recently reported NUD-2 and closely related to the CIT-13 structures, both of which contain $c f i-$ type layers linked by $\mathrm{D}_{4} \mathrm{R}$ units. ${ }^{18,19}$ Similar to CIT-13 and NUD-2 a high degree of disorder was seen in the framework structure. The 10-ring channels are difficult to see in the TEM images (Figure $3 \mathrm{E}$ and $\mathrm{F}$ ) because they are 'blocked' by the disorder of the $\mathrm{D}_{4} \mathrm{R}$ units and by signifncant stacking faults in the material, giving rise to the high degree of mosaicity in the 110 direction, visible in Figures $3 \mathrm{C}$ and $3 \mathrm{D}$. As described above SAZ-1 and NUD-2 have the same refined crystal structure. The only difference between SAZ-1 and CIT-13 is the observed unit cell size; in CIT-13 it is doubled in the c-direction indicating a different disorder pattern of the $\mathrm{D}_{4} \mathrm{R}$ units. It should be noted that the SDA used in the synthesis of SAZ-1 is different from those used in the synthesis of NUD-2 and CIT-13, indicating that the choice of SDA has an important effect on the disorder patterns in the material, which in turn could affect the properties of the materials in subtle ways.

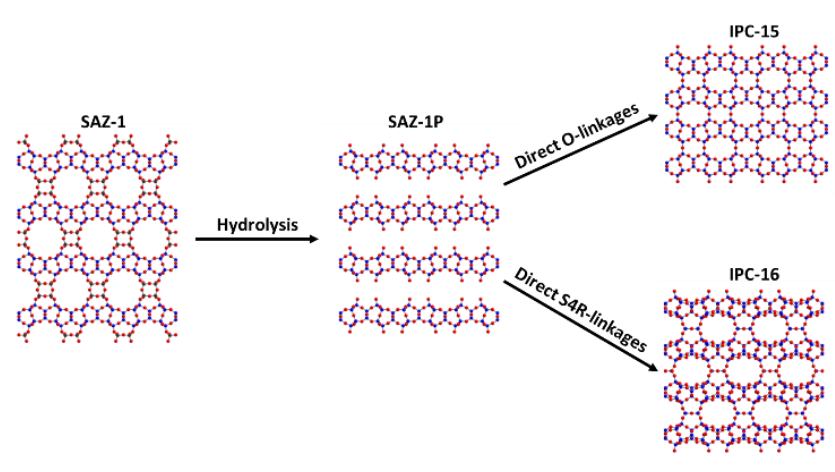

Figure 4. A Schematic representation of SAZ-1 and the products after the application of the ADOR process as viewed along the c-axis. Showing the removal of $\mathrm{Ge}$ containing $\mathrm{D}_{4} \mathrm{R}$ connections between the layers to form the lamellar product SAZ-1P. SAZ-1P can then be treated with octylamine $\left(75^{\circ} \mathrm{C}\right.$ for $3 \mathrm{hr}$, RT for $\left.16 \mathrm{hrs}\right)$ and calcination $\left(575^{\circ} \mathrm{C}\right)$ to create direct O-linkages between the layers to form IPC-15. Or SAZ-1P can be treated with diethoxydimethylsilane under acidic conditions (1M HNO3, 175 ${ }^{\circ} \mathrm{C}$ ) and calcination to create $\mathrm{S}_{4} \mathrm{R}$ linkages between the layers to form IPC-16.

High-resolution spherical aberration corrected $\left(\mathrm{C}_{\mathrm{s}^{-}}\right.$ corrected) HAADF scanning transmission electron microscopy (STEM) confirmed the overall structure of the SAZ-1 material, including the one-dimensional 14-ring channels, and also showed clearly the significant faulting/disorder of the crystals (Figure 3 ).

Given the successful hydrothermal synthesis (assembly) of SAZ-1, the next stage was to proceed with the ADOR process, where the parent germanosilicate is disassembled, organized and reassembled to produce two new daughter zeolites (Figure 4).

Disassembly of SAZ-1. Treatment of SAZ-1 with o.1 M $\mathrm{HCl}$ (see experimental) resulted in a shift to higher scattering angle of the 200 reflection that determines the interlayer distance (from $6.3^{\circ}$ to $7.9^{\circ} 2 \theta$ ). This indicates the removal of the germanium-containing $\mathrm{D}_{4} \mathrm{R}$ units and decreasing interlayer distance between the silicate $(c f i)$ layers, producing a layered intermediate that we call SAZ${ }_{1} \mathrm{P}$. While there is a considerable loss of intensity of many of the peaks, consistent with a loss of crystallinity after disassembly, we also notice the preservation of some key peaks that indicate that the silicate layers remain intact after the hydrolysis. From the Pawley (structureless) fit conducted on SAZ-1P (Figure $\mathrm{S}_{7}$ ) we found, despite the limited number of peaks, a reasonable agreement of $R_{w p}=$ $0.94 \%$ for the cell Cmmm $a=22.274(3) \AA, b=13.6359(5) \AA$ and $c=4.9708(6) \AA$. The refinement of the unit cell shows that the $a$ axis decreases from $\sim 27.2 \AA$ for SAZ-1 to $22.3 \AA$ for SAZ-1P after the hydrolysis (the $a$ axis corresponds to the stacking repeat and half of this value is the interlayer spacing). The $b$ and $c$ unit cell constants remain approximately unchanged. This is consistent with the loss of the $\mathrm{D}_{4} \mathrm{R}$ linkages from the interlayer space leading to a 

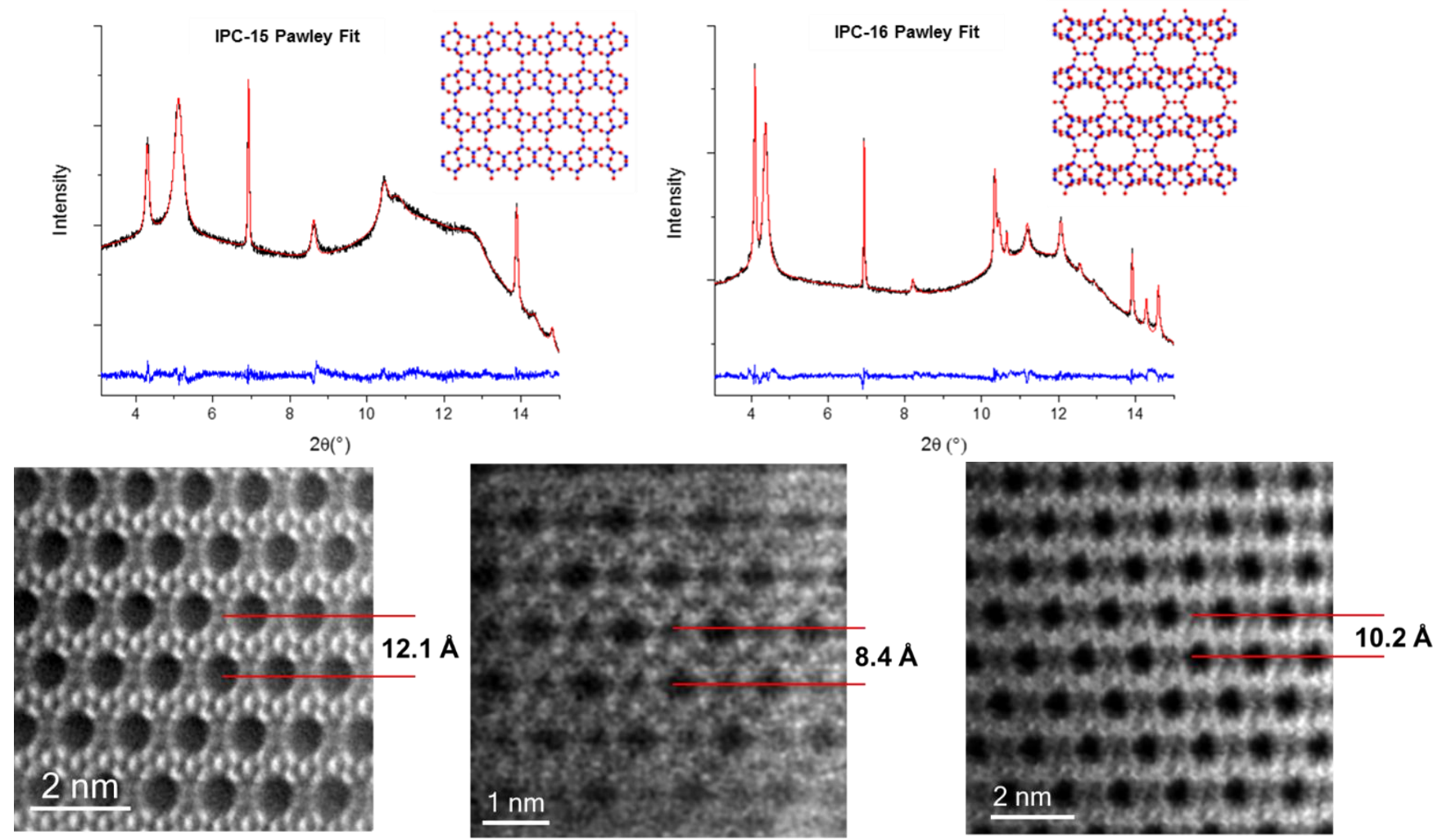

Figure 5. Pawley fits of IPC-15 (top left) and IPC-16 (top right) with their respective computationally predicted structures as viewed along the c-axis showing the experimental PXRD (black), calculated (red) and difference curves (blue). Both showed very good fits for the unit cells where the silicate layers were connected by direct O-linkages and $\mathrm{S}_{4} \mathrm{R}$ linkages respectively. Also presented are the high-resolution TEM images (bottom) of SAZ-1, IPC-15 and IPC-16 (left to right).

contraction of the cell by about $4.9 \AA$, similar to that seen for other ADOR processes. ${ }^{20,21}$ EDX and SEM analysis confirmed the removal of germanium and the preservation of the original SAZ-1 morphology (Figure $S_{3}$ ).

Formation of IPC-15 and IPC-16. The hydrolyzed intermediate, SAZ-1P, was then treated in two ways to form the two daughter zeolites (see experimental). These procedures correspond to the organization and reassembly stages of the ADOR process (Figure 4). One of the great attractions of the ADOR process is once we know the structure of the layers involved it is relatively easy to anticipate the structures of the ADOR products, ${ }^{22}$ and the target models for the ADOR daughter zeolites were predicted by taking the SAZ-1P structure derived from the original SAZ-1 structure and connecting the layers in various different ways. In this regard two daughter zeolites with the same layers but with different linkages between these layers were predicted. IPC-15 consists of SAZ-1P layers connected by O-linkages and IPC-16 consists of SAZ${ }_{1} \mathrm{P}$ layers connected by $\mathrm{S}_{4} \mathrm{R}$ linkages. In this way two new materials were computationally predicted as possible ADOR products and their structural models optimized using DFT, ${ }^{22}$ (see supplementary information).
Treatment of SAZ-1P with octylamine followed by calcination to remove the organic SDA resulted in the formation of a new $3 \mathrm{D}$ framework zeolite. The powder X-ray diffraction matches the calculated pattern from DFToptimized models that comprise the SAZ-1P layers connected by direct oxygen linkers (IPC-15). Treatment of SAZ-1P with a source of silicon (diethoxydimethylsilane) under acidic conditions at $175{ }^{\circ} \mathrm{C}$ with subsequent calcination yielded another new $3 \mathrm{D}$ zeolite (IPC-16). The XRD from this material matched that from the DFT-calculated model comprising SAZ-1P layers connected by single four ring $\left(\mathrm{S}_{4} \mathrm{R}\right)$ units. The unit cells of the daughter products were derived from Pawley fits against the diffraction patterns (Figure 5), using the DFT-derived unit cells as starting points. These two separate refinements converged to similar unit cells that differ along the a-axis. The refined unit cells match well with those predicted from the computational work for IPC-15 and IPC-16. SEM images showed the preservation of the rectangular thin-plate crystals and EDX confirmed the removal of germanium (Figure $S_{3}$ ). High-resolution spherical aberration corrected $\left(\mathrm{C}_{\mathrm{s}}\right.$-corrected) scanning transmission electron microscopy images (STEM) obtained also confirmed the successful application of the ADOR process and what we had 
observed in the changing powder patterns. The silicate layers from SAZ-1 remained intact and the linkages manipulated so that the daughter zeolites showed an isoreticular relationship with their parent zeolite. This is clearly seen in the changing distance between the silicate layers of the three structures (Figure 5). SAZ-1 shows the largest interlinkage distance (12.1 $\AA$ ), as the silicate layers are connected by $\mathrm{D}_{4} \mathrm{R}$ linkages. In contrast IPC-15 shows the smallest interlinkage distance $(8.4 \AA)$ as the silicate layers have contracted closer together to form direct $\mathrm{O}$ linkages between the layers. While IPC-16 lies between the two (10.2 $\AA$ ) as the silicate layers are connected by $S_{4} R$ linkages. These distances are similar to that predicted from the DFT-derived cells. The images also showed the changing size of the ring channels between the three materials, further corroborating that SAZ-1, IPC-15 and IPC16 show a clear isoreticular relationship with each other. This was also noted from the adsorption data where there was a decrease in BET-calculated surface area from SAZ-1 $>$ IPC-16 > SAZ-1P > IPC-15 corresponding to the decrease in the interlayer distance observed in the PXRD and HRSTEM data and the expected reduction in pore size through the system.

The HR-STEM images and the PXRD data collected showed that there was a large degree of disorder in both daughter zeolites. This is most likely due to the disorder already present in the parent SAZ-1 germanosilicate. In other words the disorder present in the parent zeolites is 'passed down' to the daughter zeolites. This is not surprising as proximity of the silanol quadruplets to each other after removal of $\mathrm{D}_{4} \mathrm{R}$ units during the disassembly of the parent material must allow the same type of disorder patterns as are available in the parent.

${ }^{29}$ Si MAS NMR of SAZ-1 shows a broad signal consistent with the presence of silicon nuclei surround by different numbers of $\mathrm{Si} / \mathrm{Ge}$ atoms. After disassembly, the ${ }^{29} \mathrm{Si}$ MAS NMR spectrum of SAZ-1P (Figure 6) shows both $\mathrm{Q}^{3}$ $\left((\mathrm{SiO})_{3} \mathrm{Si}-\mathrm{OH}\right)$ and $\mathrm{Q}^{4}\left((\mathrm{SiO})_{4} \mathrm{Si}\right)$ type silicon nuclei, consistent with loss of Ge and production of silanols groups. $\left\{{ }^{1} \mathrm{H}\right\}{ }^{29} \mathrm{Si}$ cross polarisation MAS NMR experiments show the expected enhancement of the $\mathrm{Q}^{3}$ sites at around -100 $\mathrm{ppm}$. The spectra of the reassembled zeolites IPC-15 and IPC-16 show broad samples of predominantly $\mathrm{Q}^{4}$ silicon sites, with some $\mathrm{Q}^{3}$ sites present in the sample, presumably due to incomplete condensation of the silanols groups on reassembly.

In summary, we have shown the first case where a parent germanosilicate has been designed, a priori, and synthesized through traditional hydrothermal synthesis to produce a material suitable for further manipulation using the ADOR process. Taking into account the design principles discussed we synthesized a suitable SDA cation (1-methyl-3-(naphthalen-1-ylmethyl)-imidazolium cation) and used it to synthesis the parent germanosilicate SAZ-1, which was confirmed through PXRD, SEM, EDX and
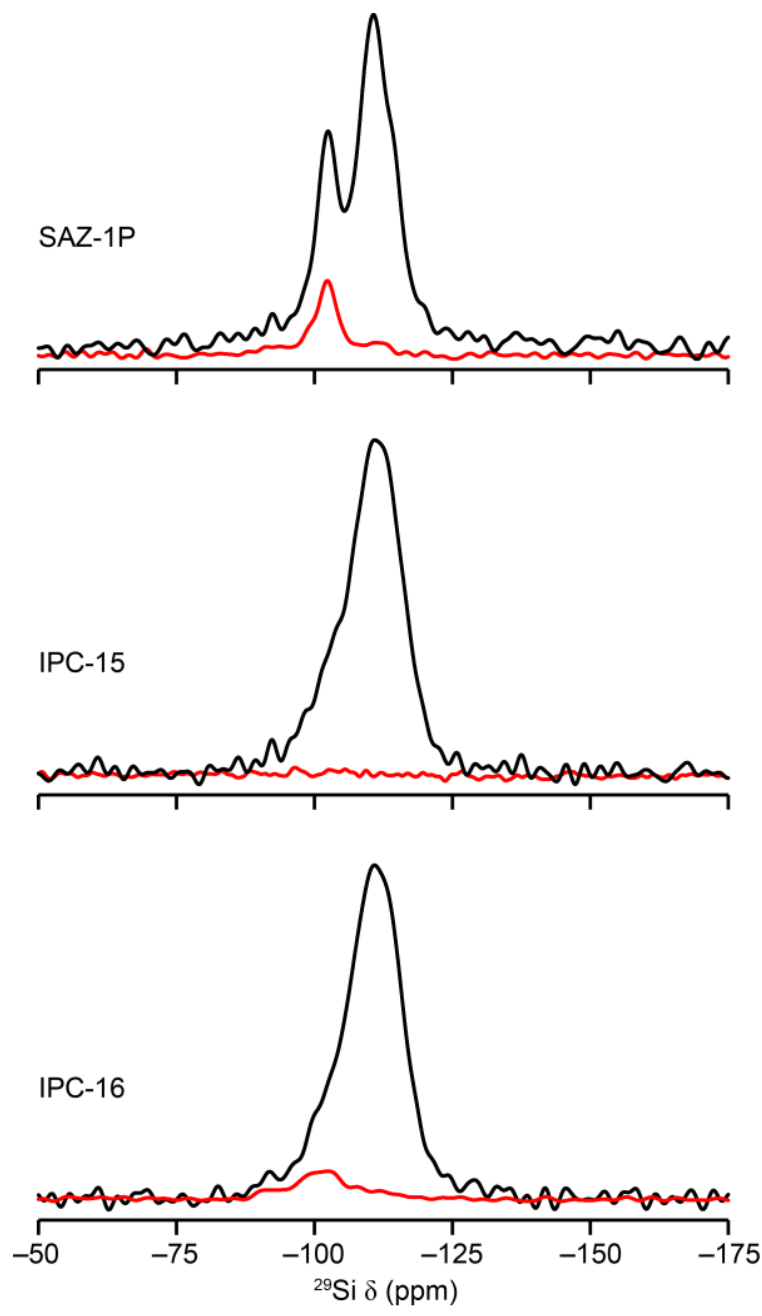

Figure 6. ${ }^{29} \mathrm{Si}$ MAS NMR spectra (black) and $\left\{{ }^{1} \mathrm{H}\right\}{ }^{29} \mathrm{Si}$ cross polarisation MAS NMR (red) of SAZ-1P, IPC-15 and IPC-16. SAZ-1P shows a relatively large number of $\mathrm{Q}^{3}$ sites caused by the removal of the Ge-dominated $\mathrm{D}_{4} \mathrm{R}$ linkages to leave silanol groups. IPC-15 and IPC-16 show the presence of predominantly $\mathrm{Q}^{4}$ sites confirming the reconnection of the silicate layers.

$\mathrm{C}_{\mathrm{s}}$-corrected HRSTEM and found to be similar to CIT-13 and NUD-2.

We then used the ADOR process to remove the germanium-containing $\mathrm{D}_{4} \mathrm{R}$ and subsequently create new connections between the silicate layers. This formed two new daughter zeolites, whose frameworks have not been previously synthesized: IPC-15 (where the layers are connected by direct O-linkages) and IPC-16 (where the layers are connected by $\mathrm{S}_{4} \mathrm{R}$ linkages), which we identified by comparison of the materials with predicted model structures and through the use of HRSTEM images. We confirmed the removal of germanium by EDX and the preservation of the morphology was confirmed by SEM. Overall, we have shown that a carefully designed hydrothermal synthesis can be used to provide a material that is amenable to the ADOR process. This is the first case where a parent germanosilicate has been designed and then the number 
of possible frameworks amplified through the ADOR process.

\section{ASSOCIATED CONTENT}

Notes. Details for the cells of the corresponding structures. SAZ-1 unit cell Cmmm $a=27.562(15) \AA, b=13.758(6) \AA$ and $c=$ $5.108(2) \AA$ a complete description of the framework topology can be found in reference 18 .

SAZ-1P pawley fit $\mathrm{R}_{\mathrm{wp}}=0.94 \%$ and $\mathrm{R}_{\mathrm{exp}}=0.63 \%$ for the cell Cmmm $a=22.274(3) \AA, b=13.6359(5) \AA$ and $c=4.9708(6) \AA$.

IPC-15 pawley fit $\mathrm{R}_{\mathrm{wp}}=0.73 \%$ and $\mathrm{R}_{\mathrm{exp}}=0.66 \%$, were obtained for the cell Cmmm $a=18.489$ (2) $\AA, b=13.651(1) \AA$ and $c$ = 4.972(1) $\AA$.

IPC-16 pawley fit $\mathrm{R}_{\mathrm{wp}}=0.87 \%$ and $\mathrm{R}_{\mathrm{exp}}=0.63 \%$ were obtained for the cell $\mathrm{Cmmm} a=21.617(1) \AA, b=13.6264(8) \AA$ and $c=$ $9.9770(7) \AA$. The $c$-axis is doubled in the predicted IPC-16 compared to IPC-15 because of the disorder present in the framework.

Supporting Information. Contains ${ }^{1} \mathrm{H}$ NMR spectrum of SDA used, SEM images and EDX results of materials made, TGA data and ${ }^{13} \mathrm{C}$ NMR and enlarged STEM images of SAZ-1, Pawley refinement and 29 Si MAS NMR of SAZ-1P and DFT calculation information for predicted structures of IPC-15 and IPC-16. This material is available free of charge via the Internet at http://pubs.acs.org.

\section{AUTHOR INFORMATION}

\section{Corresponding Author}

*E-mail: remı@st-andrews.ac.uk.

\section{Author Contributions}

The manuscript was written through contributions of all authors. / All authors have given approval to the final version of the manuscript. DSF thought of the initial concept, synthesised the materials and wrote this paper with REM. SAM and PSW did X-ray powder diffraction data collection and Pawley refinement. SER and AM collected TEM images. AMZS performed single crystal analysis. DMD collected and analysed MAS NMR data. MP and PN provided the computational models. MO and JČ provided academic discussion and guidance.

\section{ACKNOWLEDGMENTS}

We thank the EPSRC (EP/Ko25112/1) for funding work in this area. R.E.M., J.Č. and P.N. acknowledge the Czech Science Foundation for the project P106/12/Go15 and OP VVV "Excellent Research Teams", project No. CZ.02.1.01/o.o/o.o/15_003/0000417 - CUCAM.

\section{REFERENCES}

(1) Cundy, C. S.; Cox, P. A. The hydrothermal synthesis of zeolites: History and development from the earliest days to the present time. Chem. Rev. 2003, 103, 663-701.

(2) Cundy, C. S.; Cox, P. A. The hydrothermal synthesis of zeolites: Precursors, intermediates and reaction mechanism. Microporous Mesoporous Mater. 2005, 82, 178.

(3) Li, J.; Corma, A.; Yu, J. Synthesis of new zeolite structures. Chem. Soc. Rev. 2015, 44, 7112-7127.

(4) Weckhuysen, B. M.; Yu, J. Recent advances in zeolite chemistry and catalysis. Chem. Soc. Rev. 2015, 44, 70227024 .
(5) Li, X.; Deem, M. W. Why Zeolites Have So Few SevenMembered Rings. J. Phys. Chem. C 2014, 118, 15835-15839. Blatov, V. A.; Ilyushin, G. D.; Proserpio, D. M. The zeolite conundrum: Why are there so many hypothetical zeolites and so few observed? A possible answer from the zeolitetype frameworks perceived as packings of tiles. Chem. Mater. 2013, 25, 412-424.

(7) Pophale, R.; Cheeseman, P. a; Deem, M. W. A database of new zeolite-like materials. Phys. Chem. Chem. Phys. 2011, 13, 12407-12412.

(8) Morris, R. E.; Čejka, J. Exploiting chemically selective weakness in solids as a route to new porous materials. Nat. Chem. 2015, 7, 381-388.

(9) Roth, W. J.; Nachtigall, P.; Morris, R. E.; Čejka, J. TwoDimensional Zeolites: Current Status and Perspectives. Chem. Rev. 2014, 114, 4807-4837.

(10) Mazur, M.; Wheatley, P. S.; Navarro, M.; Roth, W. J.; Položij, M.; Mayoral, A.; Eliášová, P.; Nachtigall, P.; Čejka, J.; Morris, R. E. Synthesis of "unfeasible" zeolites. Nat. Chem. 2015, 8, 58-62.

(11) Roth, W. J.; Nachtigall, P.; Morris, R. E.; Wheatley, P. S.; Seymour, V. R.; Ashbrook, S. E.; Chlubná, P.; Grajciar, L.; Položij, M.; Zukal, A.; et al. A family of zeolites with controlled pore size prepared using a top-down method. Nat. Chem. 2013, 5, 628-633.

(12) Wheatley, P. S.; Čejka, J.; Morris, R. E. Synthesis of Zeolites Using the ADOR (Assembly-Disassembly-OrganizationReassembly) Route. J. Vis. Exp. 2016, 110, e53463.

(13) Eliášová, P.; Opanasenko, M.; Wheatley, P. S.; Shamzhy, M. Mazur, M.; Nachtigall, P.; Roth, W. J.; Morris, R. E.; Čejka, J. The ADOR mechanism for the synthesis of new zeolites. Chem. Soc. Rev. 2015, 44, 7177-7206.

(14) Wragg, D. S.; Morris, R. E.; Burton, A. W. Pure silica zeolite-type frameworks: A structural analysis. Chem. Mater. 2008, 20, 1561-1570.

(15) Sastre, G.; Vidal-Moya, J. A.; Blasco, T.; Rius, J.; Jordá, J. L.; Navarro, M. T.; Rey, F.; Corma, A. Preferential location of Ge atoms in polymorph $\mathrm{C}$ of beta zeolite (ITQ-17) and their structure-directing effect: A computational, XRD, and NMR spectroscopic study. Angew. Chemie Int. Ed. 2002, 41, 47224726.

(16) Blasco, T.; Corma, A.; Díaz-Cabañas, M. J.; Rey, F.; VidalMoya, J. A.; Zicovich-Wilson, C. M.; Díaz-Cabañ, J.; Rey, F.; Vidal-Moya, J. A.; Zicovich-Wilson, C. M. Preferential location of $\mathrm{Ge}$ in the double four-membered ring units of ITQ-7 zolite. J. Phys. Chem. B 2002, 106, 2634-2642.

(17) Chen, F.-J.; Xu, Y.; Du, H.-B. An Extra-Large-Pore Zeolite with Intersecting 18-, 12-, and 10-Membered Ring Channels. Angew. Chemie Int. Ed. 2014, 53, 9592-9596.

(18) Kang, J. H.; Xie, D.; Zones, S. I.; Smeets, S.; McCusker, L. B. Davis, M. E. Synthesis and Characterization of CIT-13, a Germanosilicate Molecular Sieve with Extra-Large Pore Openings. Chem. Mater. 2016, 28, 6250-6259.

(19) Gao, Z.-H.; Chen, F.-J.; Xu, L.; Sun, L.; Xu, Y.; Du, H.-B. A Stable Extra-Large-Pore Zeolite with Intersecting $14^{-}$and 10-Membered-Ring Channels. Chem. Eur. J. 2016, 22, 1436714372.

(20) Chlubná, P.; Roth, W. J.; Greer, H. F.; Zhou, W.; Shvets, O.; Zukal, A.; Čejka, J.; Morris, R. E. ${ }_{3} \mathrm{D}$ to $2 \mathrm{D}$ routes to ultrathin and expanded zeolitic materials. Chem. Mater. 2013, 25, 542-547.

(21) Roth, W. J.; Shvets, O. V.; Shamzhy, M.; Chlubná, P.; Kubů, M.; Nachtigall, P.; Čejka, J. Postsynthesis Transformation of Three-Dimensional Framework into a Lamellar Zeolite with Modifiable Architecture. J. Am. Chem. Soc. 2011, 133, 61306133.

(22) Trachta, M.; Nachtigall, P.; Bludský, O. The ADOR synthesis of new zeolites: In silico investigation. Catal. Today 2015, 243, 32-38. 
Insert Table of Contents artwork here

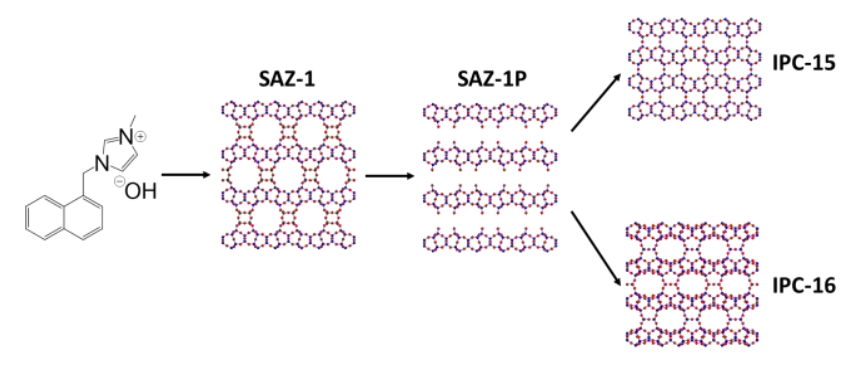

